\title{
High $T_{\mathrm{c}}$ thin films prepared by laser ablation: material distribution and droplet problem
}

\author{
D. H. A. Blank, R. P. J. IJsselsteijn, P. G. Out, H. J. H. Kuiper, J. Flokstra and H. Rogalla \\ University of Twente, Faculty of Applied Physics, P.O. Box 217, 7500 AE Enschede (Netherlands)
}

\begin{abstract}
The lateral material distribution of laser-deposited $\mathrm{YBa}_{2} \mathrm{Cu}_{3} \mathrm{O}_{7-\delta}$ films and the density of droplets coming from the target were studied by varying the laser pulse energy, the laser spot size and the target-to-substrate distance. Silicon wafers at ambient temperature were used as substrates to guarantee a large sticking coefficient of the particles. The deposition rate is found to depend linearly on the laser energy density $E$ and quadratically on the spot size $S$ at the target, whereas the droplet density is slightly dependent on $E$ and increases linearly with $1 / S$, yielding a threshold energy of $0.9 \mathrm{~J} \mathrm{~cm}^{-2}$. With a laser spot size of $7.15 \mathrm{~mm}^{2}$ and a laser energy density of $1.2 \mathrm{~J} \mathrm{~cm}^{-2}$, we were able to reduce the number of droplets to one to two per $500 \mu \mathrm{m}^{2}$ for a high quality high $T_{\mathrm{c}}$ film with a typical thickness of $100 \mathrm{~nm}$.
\end{abstract}

\section{Introduction}

In this paper a study about the laser-induced plasma of the high $T_{\mathrm{c}}$ material $\mathrm{YBa}_{2} \mathrm{Cu}_{3} \mathrm{O}_{7-\delta}$ is presented. In detail the shape of the plasma, the particle distribution and the occurrence of droplets have been investigated.

Despite the number of advantages of laser ablation compared with other deposition techniques, it has one drawback: occurrence of droplets. These droplets are small spherical particles, with a typical diameter of $0.5-2 \mu \mathrm{m}$, coming from the target and leading to rough surfaces. In the literature some attention is paid to the reduction in the number of particles by using a high density target [1] or a second laser beam parallel to the substrate, which interferes with the plume of the ablated material [2].

We report on the influence of the deposition parameters, such as the laser pulse energy, the laser spot size and the target-to-substrate distance, on the distribution of the material, including the droplets, in the laserinduced plasma. An introductory description of the physics of pulsed-laser deposition is also given and where possible we shall couple the experimental results to this theory.

From this study we can conclude that the maximum deposition rate increases with increasing energy density on the target and spot size, whereas the normalized droplet density increases with increasing energy density and decreases with increasing spot size. The two parameters, energy density at the target and spot size, can be adjusted so that the amount of droplets can be reduced to fewer than three per $500 \mu \mathrm{m}^{2}$, for a film thickness of $100 \mathrm{~nm}$.

\section{The pulsed-laser deposition process}

Four different processes play an important role during the deposition of thin layers with the laser ablation technique: (1) interaction of the laser beam with the target; (2) interaction of evaporated material with the laser beam; (3) adiabatic expansion of the plasma; (4) the specific growth kinetics of the film.

The interaction of the laser beam with the $\mathrm{YBa}_{2} \mathrm{Cu}_{3} \mathrm{O}_{7-\delta}$ target is affected by a number of parameters such as the linear absorption coefficient $\alpha$ and reflectivity $R$ of the target material, and the pulse duration $\tau$, wavelength $\lambda_{L}$ and energy of the laser beam. The frequency-dependent values of $\alpha$ and $R$ are not known exactly for $\mathrm{YBa}_{2} \mathrm{Cu}_{3} \mathrm{O}_{7-o}$. The reflectivity is also dependent on the surface roughness and impurities. Besides the uncertainty of $R$ and $\alpha$, one has to deal with non-linear effects due to the temperature-dependent absorption, the reflectivity, the diffusion, and the melting and evaporation processes. Nevertheless, some simplifying assumptions can be made. The pulse duration is very short ( $20 \mathrm{~ns})$, whereas the heat conduction and convection in the gas are slow; so the conduction and radiation losses in the gas can be neglected. Also the black-body radiation term $\sigma T^{4}$ (in the case of an ideal black-body at $T=2500 \mathrm{~K}, Q=2.22 \times 10^{2} \mathrm{~W}$ $\left.\mathrm{cm}^{-2}\right)$ is small compared with the incident laser flux of typically $10^{8} \mathrm{~W} \mathrm{~cm}^{-2}$ and can be neglected. Because of the small penetration depth compared with the laser beam dimensions, the heat transport in the target can be considered as a one-dimensional problem. If the optical absorption depth $\alpha^{-1}$ is much smaller than the thermal diffusion length $L_{\mathrm{d}}\left(=\left[2\left(\lambda / \rho c_{p}\right) t\right]^{1 / 2}\right.$, where $\lambda$ 
represents the thermal conductivity, $c_{p}$, the heat capacity per unit mass and $\rho$ the mass density of the target material), the solution the standard heat conduction equation gives the following relation between the time-dependent surface temperature and laser energy density $E$ during the pulse [3]:

$T(0, t)=\frac{2 E(1-R)}{\tau \lambda}\left(\frac{\lambda t}{\rho c_{\mathrm{p}} \pi}\right)^{1 / 2}$

and

$\left(E-E_{\mathrm{th}}\right)(1-R)=\Delta z_{\langle\ell\rangle}\left(c_{\mathrm{p}} \rho \Delta T+\rho L\right)$

where $E_{\mathrm{th}}$ represents the threshold energy density, $L$ the latent heat, $\Delta z_{(t)}$ the time-dependent evaporation depth and $\Delta T$ the difference between evaporation and ambient temperature.

Making use of the values for $\mathrm{YBa}_{2} \mathrm{Cu}_{3} \mathrm{O}_{7-\delta}[4,5]$, namely $\rho=6.68 \mathrm{~g} \mathrm{~cm}^{-3},\left\langle c_{p}\right\rangle=0.2 \mathrm{~J} \mathrm{~g}^{-1} \mathrm{~K}^{-1},\langle\lambda\rangle=2 \mathrm{~W}$ $\mathrm{cm}^{-1} \mathrm{~K}^{-1}, R=0.1$, an evaporation temperature of $2500 \mathrm{~K}$ and a threshold energy of $0.4 \mathrm{~J} \mathrm{~cm}^{-2}$, we find, when $\tau$ is $20 \mathrm{~ns}$ and taking into account that $\rho c_{p}$ $\Delta T \approx \rho L$, the following which are reasonable compared with other materials:

$E^{2} t=6.6 \times 10^{-9} \quad \Delta z_{(i)}=1.3(E-0.4) \mu \mathrm{m}$

At a laser energy density of $2 \mathrm{~J} \mathrm{~cm}^{-2}$, the time $t_{\mathrm{c}}$ needed to heat $\mathrm{YBa}_{2} \mathrm{Cu}_{3} \mathrm{O}_{7-\gamma}$ to its evaporation temperature is $1.6 \mathrm{~ns}$. This value is comparable with those of iron, aluminium or copper, which are $1.8 \mathrm{~ns}, 2.6 \mathrm{~ns}$ and $0.8 \mathrm{~ns}$ respectively [3]. The velocity $v_{\mathrm{c}}$ of the evaporation front in the target is $0.1 \mu \mathrm{m} \mathrm{ns}^{-1}$. This velocity is also comparable with the values given for a number of metals, namely $0.01-0.1 \mu \mathrm{m} \mathrm{ns}^{-1}$ [3].

The evaporated material introduces a new aspect. The laser beam, which normally only hits the target material, is scattered by the evaporated material, resulting in the absorption of laser energy. This leads to two effects. First, radiative heating of the free electrons takes place. These electrons strongly couple with the incident radiation and are accelerated. Collisions with the evaporated material increase the ionization rate. Secondly, the temperature of the evaporated material increases rapidly to extremely high values $(20000-40000 \mathrm{~K})$. These high temperatures close to the surface of the target lead to thermionic emission of ions from the target, as is the case for other thermal processes. On the one hand the evaporated material shields the target for the incident radiation, resulting in a decrease in the evaporation velocity; on the other hand, the evaporation velocity will increase owing to the radiation energy of the evaporated material at high temperatures.

The interaction of the laser beam with the ablated material leads to a very high pressure close to the target. The heated material can be represented as a gas in a small volume with high pressure in a vacuum surrounding. Because of the pressure gradient, it will expand. Because the derivative of the pressure in the $z$ direction is much larger than the derivatives in the $x$ and $y$ direction, the particles mainly move in the direction normal to the target surface. Meanwhile, the excited particles will emit photons, leading to an enhanced plasma plume, which is characteristic of the laser ablation process. The expansion of the gas in the direction to the target most probably causes the occurrence of droplets; molten material is splashed from the target and is carried away with the expanding gas in the direction of the substrate.

The growth kinetics of the film prepared by laser ablation are different from those of other deposition techniques: the plasma contains a diversity of particles, such as $\mathrm{Cu}^{+}, \mathrm{Ba}^{+}, \mathrm{Cu}, \mathrm{O}_{2}{ }^{+}, \mathrm{Y}, \mathrm{BaO}, \mathrm{YO}$ and $\mathrm{CuO}[6]$, all in a vapour phase, there are no electric fields or accelerated noble gas ions present and the material is offered, in large quantities, to the substrate in a pulsed way.

\section{Experimental details}

The equipment used for the deposition of the layers has been described in a previous paper [7] and as such is only briefly mentioned here. An excimer laser in the $\mathrm{XeCl}$ mode $(308 \mathrm{~nm})$ is used with a maximum pulse energy of $150 \mathrm{~mJ}$. The size of the laser beam is $23 \mathrm{~mm}$ ( $x$ direction) by $12 \mathrm{~mm}$ ( $y$ direction) with a maximum repetition frequency of $100 \mathrm{~Hz}$ and a pulse duration of $20 \mathrm{~ns}$. The laser beam is focused onto the target using a 2 in quartz lens with a focal length of $500 \mathrm{~mm}$. The target is placed on a rotating $(10 \mathrm{~Hz})$ multiple-target holder. The $\mathrm{Y}-\mathrm{Ba}-\mathrm{Cu}-\mathrm{O}$ target is prepared by the citrate pyrolysis method [8] and has a density of approximately $80 \%$, as determined by immersion into a mercurial bath. The spot size of the laser beam can be adjusted by changing the position of the lens which is placed outside the ablation chamber. The substrate is placed parallel to the target at a variable distance.

The deposition took place under the laser ablation conditions, similar to the adjustments for the fabrication of high quality $\mathrm{Y}-\mathrm{Ba}-\mathrm{Cu}-\mathrm{O}$ thin films on $\mathrm{SrTiO}_{3}$ and $\mathrm{ZrO}_{2}$ [7]: an oxygen pressure of $25 \mathrm{~Pa}$, a laser repetition rate of $2 \mathrm{~Hz}$, a target rotation of $10 \mathrm{~Hz}$, and an angle between the target and laser beam of $45^{\circ}$. The number of pulses during each deposition was 1200 . The substrate was a 2 in silicon wafer at ambient temperature. Because of the low temperature of the silicon, all the material (including the droplets coming from the target) hitting the silicon will stick to it, creating an amorphous $\mathrm{YBa}_{2} \mathrm{Cu}_{3} \mathrm{O}_{x}$ layer. 
The deposited material distribution is directly obtained from the thickness profiles of the deposited layer on the silicon wafers. To determine the thickness profiles, an $18 \times 18$ grid consisting of $0.5 \mathrm{~mm} \times 0.5 \mathrm{~mm}$ holes, $2 \mathrm{~mm}$ apart, is etched in the amorphous layer using standard photoresist and diluted $\mathrm{H}_{3} \mathrm{PO}_{4}$ as etchant. The thickness is measured with an Alpha stepper.

The droplet density of the deposited layers has been studied using the same preparation conditions as described above. The number of droplets is counted by digitizing the photographs, obtained with an optical microscope from the surface of the deposited layer, by means of a video camera with computer.

\section{Results}

\subsection{Deposited material distribution}

The distribution of the ablated material, the ionized and neutral species, within the plasma has been studied by means of thickness profiles of layers, which are deposited under different process conditions. The spot area $S$ of the laser beam on the target, the laser energy and the distance between target and substrate were varied.

A series of layers is made at two different spot sizes, $1.45 \mathrm{~mm} \times 0.55 \mathrm{~mm}$ (series I) and $2.8 \mathrm{~mm} \times 0.9 \mathrm{~mm}$ (series II) at different laser energies, keeping the targetto-substrate distance at $35 \mathrm{~mm}$. The most relevant deposition conditions are given in Table 1 (series I) and 2 (series II). Also the maximum thicknesses, the full widths at half-maximum (FWHMs) in the $x$ and $y$ directions, and the laser energy densities are given in the tables.

In Figs. 1 and 2 the topographic plots of the thickness profiles of the deposited layers are given in the case of a laser beam energy of $88 \mathrm{~mJ}$. The plots show remarkable differences between the thickness profiles. The maximum thickness is four times smaller in the case of series I than in the case of series II (about 100 $\mathrm{nm}$ and $400 \mathrm{~nm}$ respectively), although the laser beam energy density is about three times higher. The spatial distribution of the plasma is shifted from a spherical (series I) to a conical-like shape (series II), leading to a change in the shape of the plasma in the $x-y$ plane from circular (series I) to elliptical (series II), which can be clearly seen in the corresponding topographic figures, Figs. 1 and 2.

The normalized thickness variations in two perpendicular directions with the normal of the substrate surface are plotted in Fig. 3. The cross-sections are taken in such a way that the origin of the coordinate system lies at the position of the maximum height of the deposited layer, as is specified in the topographic figures, Figs. 1 and 2 . Note that the $x$ direction is parallel to the long edge of the laser spot.

To investigate the influence of the spot size $S$ on the film thickness, a series of experiments (series III) has been performed with constant laser energy and

TABLE 1. The maximum thicknesses of the deposited layer, the full widths at half-maximum in the $x$ and $y$ directions, and the (normalized) droplet densities with constant spot size and various laser energies

\begin{tabular}{llllllll}
\hline $\begin{array}{l}\text { Laser } \\
\text { energy } \\
(\mathrm{mJ})\end{array}$ & $\begin{array}{l}\text { Spot } \\
\text { size } S \\
\left(\mathrm{~mm}^{2}\right)\end{array}$ & $\begin{array}{l}\text { Energy } \\
\text { density } \\
\left(\mathrm{J} \mathrm{cm}^{-2}\right)\end{array}$ & $\begin{array}{l}\text { Maximum } \\
\text { thickness } \\
(\mathrm{nm})\end{array}$ & $\begin{array}{l}\text { FWHM, } \\
x \text { direction } \\
(\mathrm{mm})\end{array}$ & $\begin{array}{l}\text { FWHM, } \\
y \text { direction } \\
(\mathrm{mm})\end{array}$ & $\begin{array}{l}\text { Number of } \\
\text { of droplets } \\
\left(100 \mu \mathrm{m}^{2}\right)\end{array}$ & $\begin{array}{l}\text { Normalized } \\
\text { number } \bar{N}\end{array}$ \\
\hline 98 & 0.80 & 12.25 & 120 & 25.0 & 27.0 & 35.0 & 290 \\
88 & 0.80 & 11.0 & 112 & 25.2 & 28.2 & 21.3 & 230 \\
78 & 0.80 & 9.75 & 99 & 25.0 & 28.0 & 13.8 & 164 \\
68 & 0.80 & 8.5 & 84 & 26.0 & 27.5 & 14.0 & 190 \\
58 & 0.80 & 7.25 & 73 & 25.5 &
\end{tabular}

TABLE 2. The maximum thicknesses of the deposited layer, the full widths at half-maximum in the $x$ and $y$ directions, and the (normalized) droplet densities with constant spot size and various laser energies

\begin{tabular}{|c|c|c|c|c|c|c|c|}
\hline $\begin{array}{l}\text { Laser } \\
\text { energy } \\
(\mathrm{mJ})\end{array}$ & $\begin{array}{l}\text { Spot } \\
\text { size } S \\
\left(\mathrm{~mm}^{2}\right)\end{array}$ & $\begin{array}{l}\text { Energy } \\
\text { density } \\
\left(\mathrm{J} \mathrm{cm}^{-2}\right)\end{array}$ & $\begin{array}{l}\text { Maximum } \\
\text { thickness } \\
(\mathrm{nm})\end{array}$ & $\begin{array}{l}\text { FWHM, } \\
x \text { direction } \\
(\mathrm{mm})\end{array}$ & $\begin{array}{l}\text { FWHM, } \\
y \text { direction } \\
(\mathrm{mm})\end{array}$ & $\begin{array}{l}\text { Number of } \\
\text { of droplets } \\
\left(100 \mu \mathrm{m}^{2}\right)\end{array}$ & $\begin{array}{l}\text { Normalized } \\
\text { number } \bar{N}\end{array}$ \\
\hline 98 & 2.52 & 3.9 & 437 & 29.0 & 51.0 & 15.5 & 35 \\
\hline 88 & 2.52 & 3.5 & 396 & 30.0 & 52.0 & 7.5 & 19 \\
\hline 78 & 2.52 & 3.1 & 361 & 28.5 & 53.0 & 7.7 & 21 \\
\hline 68 & 2.52 & 2.7 & 301 & 28.0 & 52.0 & 6.9 & 23 \\
\hline 58 & 2.52 & 2.3 & 211 & 27.5 & 54.0 & 7.0 & 30 \\
\hline
\end{tabular}




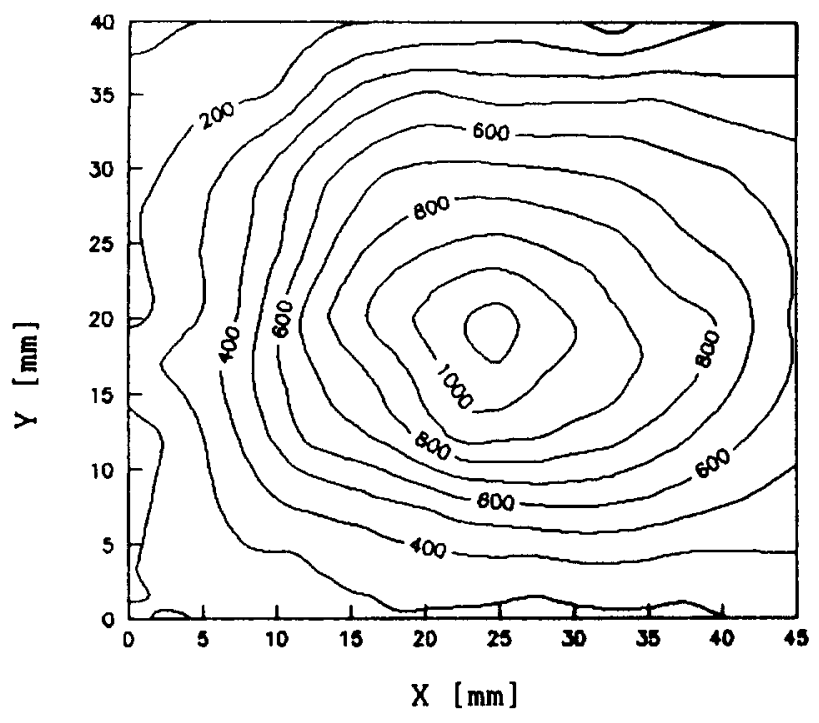

Fig. 1. Spherical thickness profile $(\AA)$ of the particle distribution of series I, with a spot size of $1.45 \mathrm{~mm}$ by $0.55 \mathrm{~mm}$ and a laser beam energy of $88 \mathrm{~mJ}$.

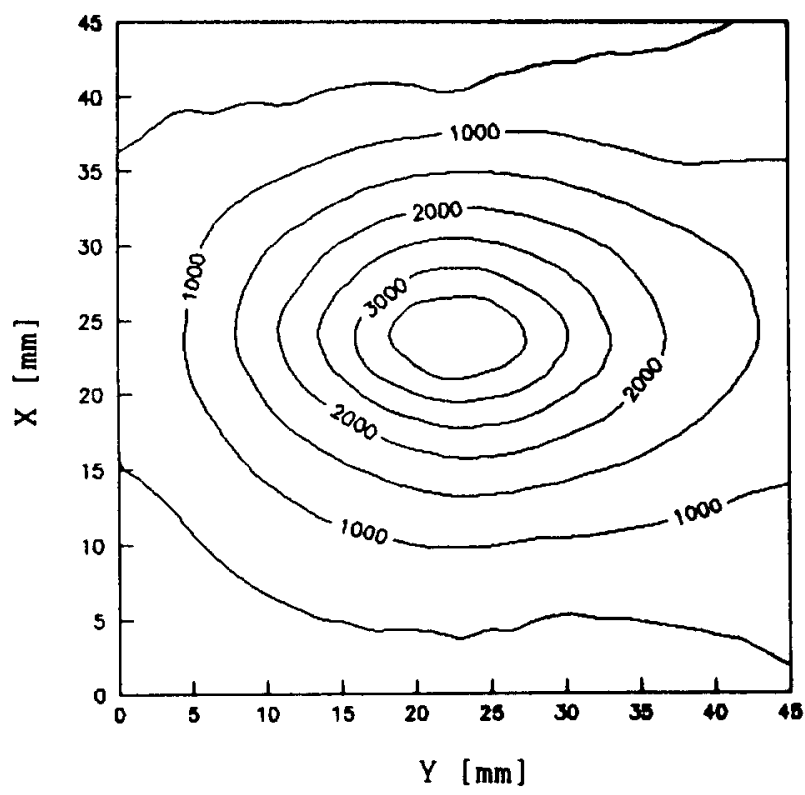

Fig. 2. Ellipsoidal thickness profile $(\AA)$ of the particle distribution of series II, with a spot size of $2.8 \mathrm{~mm}$ by $0.9 \mathrm{~mm}$ and a laser beam energy of $88 \mathrm{~mJ}$.

increasing $S$. The normalized spatial distributions of these layers are equal to the curves shown in Fig. 3. The maximum thickness scales linearly with $S$. Note that the energy density decreases with increasing $S$. The most relevant data are given in Table 3 .

The profile of the material distribution in the plasma in the $z$ direction is studied by varying the position of the substrate. The effect of the substrate plus holder on
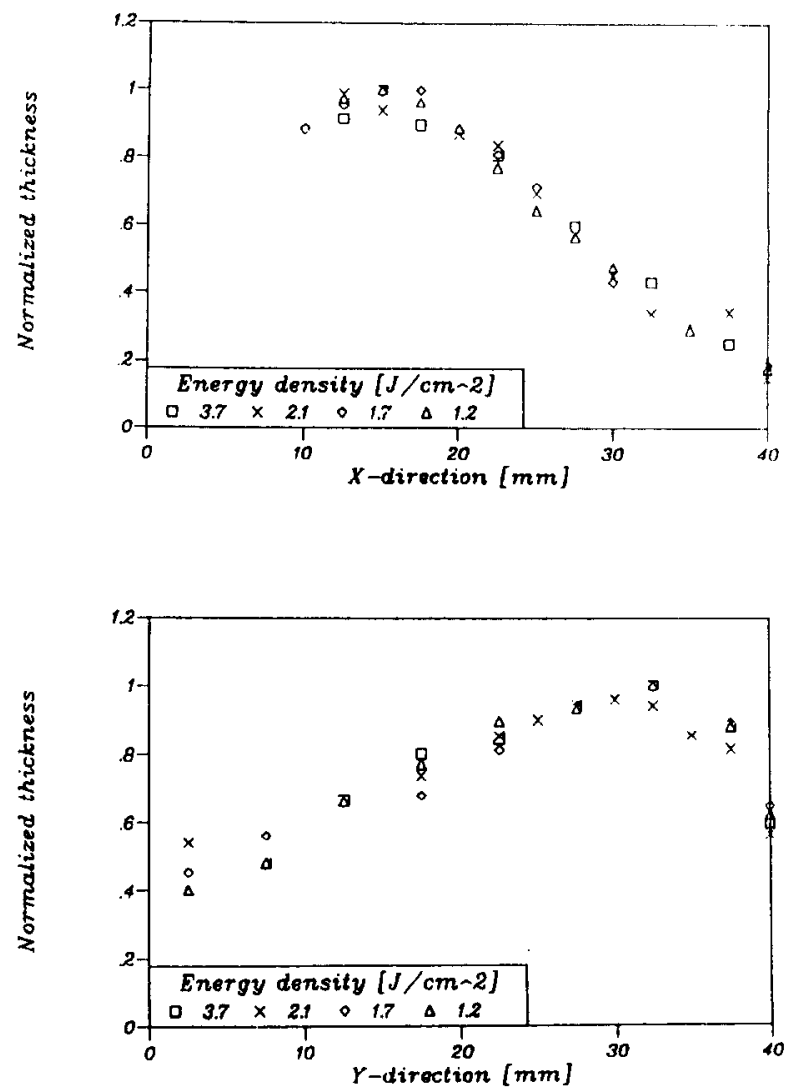

Fig. 3. Normalized thickness variation in the $x$ and $y$ directions with constant laser energy and different spot sizes (see Table 3 ).

this distribution is neglected. Figure 4 shows the thickness variation by topographic pictures, if the substrate is placed at distances of $35 \mathrm{~mm}, 45 \mathrm{~mm}$ and $55 \mathrm{~mm}$ respectively. The obtained data are given in Tables 3 and 4.

\subsection{Droplet problem}

The influence of the spot size $S$ and the laser energy on the number of droplets has been studied, using the same conditions as for the deposited material distribution studies. Figures 5(a) and 5(b) show the photographs obtained with an optical microscope from the surface of the layers of series I and II respectively deposited with a laser energy of $88 \mathrm{~mJ}$. It can clearly be seen that the series I film has a significantly higher droplet density than the series II film. In Tables 1-4 the number of droplets counted in an area of $100 \mu \mathrm{m}^{2}$ is given.

The number of droplets per unit area is proportional to the thickness of the layer. To show the influence of the laser energy and spot size $S$ on the number of droplets, the density is normalized with respect to an effective thickness of $1 \mu \mathrm{m}$, indicated by $\bar{N}$ and also given in the tables. 
TABLE 3. The maximum thicknesses of the deposited layer, the full widths at half-maximum in the $x$ and $y$ directions, and the (normalized) droplet densities with constant laser energy and various spot sizes

\begin{tabular}{lllllllr}
\hline $\begin{array}{l}\text { Laser } \\
\text { energy } \\
(\mathrm{mJ})\end{array}$ & $\begin{array}{l}\text { Spot } \\
\text { size } S \\
\left(\mathrm{~mm}^{2}\right)\end{array}$ & $\begin{array}{l}\text { Energy } \\
\text { density } \\
\left(\mathrm{J} \mathrm{cm}^{-2}\right)\end{array}$ & $\begin{array}{l}\text { Maximum } \\
\text { thickness } \\
(\mathrm{nm})\end{array}$ & $\begin{array}{l}\text { FWHM, } \\
x \text { direction } \\
(\mathrm{mm})\end{array}$ & $\begin{array}{l}\text { FWHM, } \\
y \text { direction } \\
(\mathrm{mm})\end{array}$ & $\begin{array}{l}\text { Number of } \\
\text { of droplets } \\
\left(100 \mu \mathrm{m}^{2}\right)\end{array}$ & $\begin{array}{l}\text { Normalized } \\
\text { number }\end{array}$ \\
\hline 90 & 1.4 & 6.4 & 188 & 30.0 & 50.2 & 23.0 & 120 \\
90 & 2.43 & 3.7 & 300 & 31.0 & 53.0 & 14.4 & 48 \\
90 & 4.24 & 2.1 & 480 & 30.2 & 56.0 & 13.0 & 27 \\
90 & 5.27 & 1.7 & 550 & 30.0 & 55.0 & 5.8 & 11 \\
90 & 7.32 & 1.2 & 750 & 30.2 & 55.0 & 3.1 & 4 \\
\hline
\end{tabular}

In Fig. 6 the logarithm of $\bar{N}$ is given as a function of the energy of the laser beam on the target. Series I (Table 1) is represented by full squares, series II (Table 2) by full inverted triangles, and series III (Table 3 ) by crosses.

\section{Discussion}

\subsection{Deposited material distribution}

The thickness variation in the $x$ direction is different from that in the $y$ direction, except in the case of the minimum spot size, as shown in Fig. 3. The FWHM values differ by a factor of 2 . The velocity of the evaporated target material is imposed by the pressure gradient. This pressure gradient, which is proportional to the acceleration of the evaporated material, differs in all three directions. The gradient is the highest in the $z$ direction, leading to the characteristic forward direction of the plasma material. The higher gradient in the $y$ direction, compared with the $x$ direction, leads to a higher acceleration of the material in the $y$ direction, causing a pattern in the $x-y$ plane of the ablated material on the silicon wafer rotated by $\pi / 2$ compared with the projection of the laser spot on the target. If the $x$ and $y$ directions of the volume, where the strong interaction between incident beam and evaporated material takes place, equal the dimension in the $z$ direction, one expects an acceleration that has to a good approximation equal components in all directions, resulting in a spherically shaped plasma, as is observed in the case of a spot size of $0.8 \mathrm{~mm}^{2}$.

The results presented in Tables 1 and 2 show a linear relationship between the laser energy and the maximum film thickness $d$, for constant $S$. This behaviour follows directly from the evaporation depth $\Delta z_{(t)}$ $\left(E \gg E_{\text {th }}\right)$. If we compare both tables, we also find that the maximum film thickness is directly proportional to $S$, although the energy density decreases. This behaviour is confirmed by the measurements with constant laser energy and increasing $S$, as presented in Table 2 .
Again $d$ is directly proportional to $S$. Accounting for the decrease in the laser energy density $E$, the above leads to the following relation for the film thickness:

$d \propto S^{2} E$

The distribution of the material in the $x-y$ plane of the plasma at various $z$ positions of the substrate, as presented in Table 4 and Fig. 4, leads to the following results. The maximum thickness of the deposited layers for distances smaller than $45 \mathrm{~mm}$ remains almost constant. It may be expected that the sticking coefficient will be below unity when the substrate is placed inside the plasma, thus reducing the effect of a higher particle flux at small target-to-substrate distance. The maximum thickness decreases abruptly if the distance exceeds $55 \mathrm{~mm}$. This is also the outer edge of the (bright) plasma formed by the excited particles. The deposited layer becomes very soft at larger distances. At a distance of $75 \mathrm{~mm}$ it was not possible to measure the thickness profile. Even with the lowest needle pressure of the Alpha Step instrument the needle cuts a groove into the amorphous layer, indicating that the density of the layer has a low value. So the deposition rate at these large distances decreases more rapidly than is suggested by the film thickness measurements.

It can be seen from the three-dimensional plots in Fig. 4 that two mechanisms are involved in the material distribution of the laser ablation process. The film thickness measurements show the appearance of a forward-peaked component, with a very strong angle dependence $(\mathrm{a} \cos -\gamma \theta$ distribution, with $\gamma>10)$ and a $\cos -\theta$ distribution, which can be explained by the thermalization of the material due to collisions, resulting in a maxwellian velocity distribution.

The studies presented here give information about the spatial distribution of the particles in the plasma. One has to keep in mind that in the case of depositing films at high temperatures the sticking factor decreases. The migrations of the atoms over the substrate, reevaporation and collisions of adsorbed atoms lead to a 

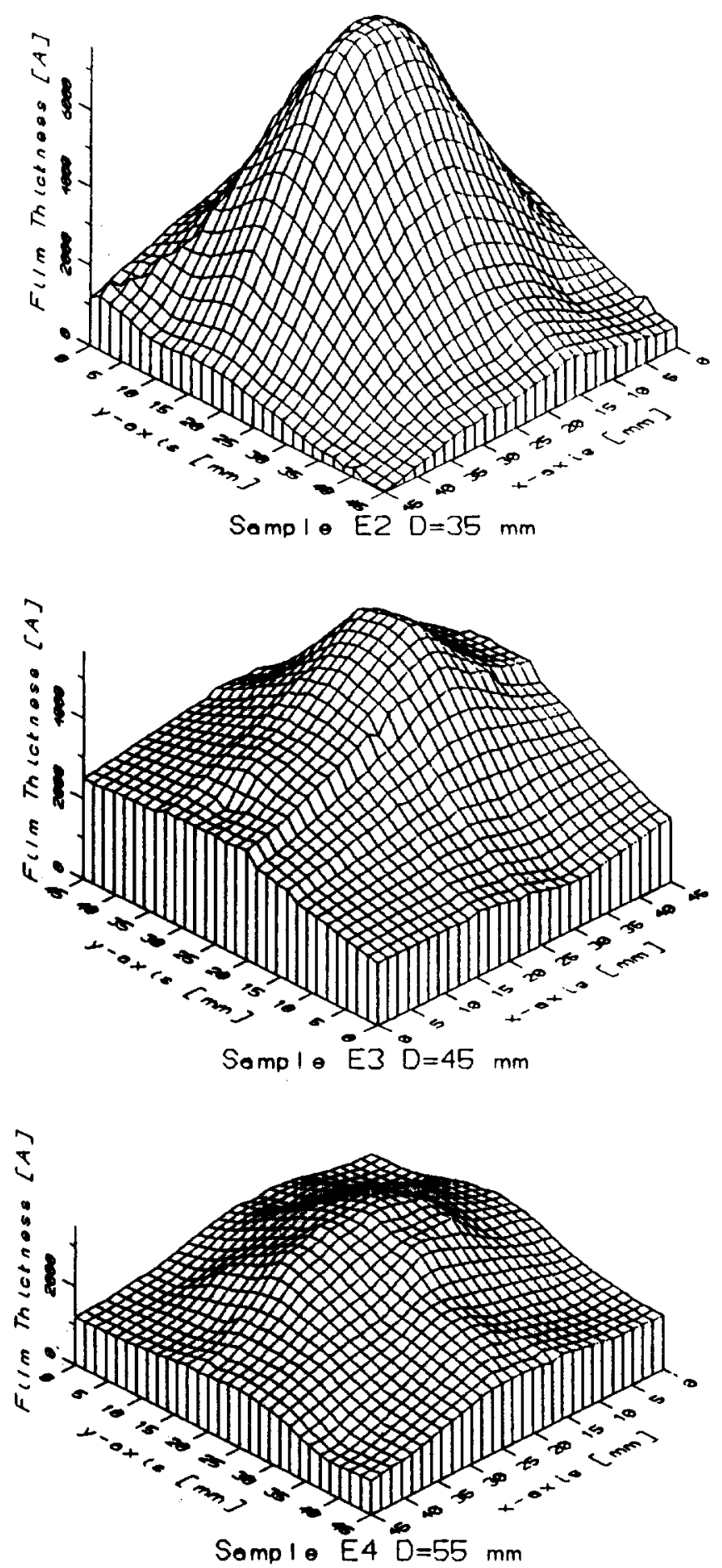

Fig. 4. Three-dimensional plots of the thickness profile $(\AA)$ of the deposited material at different substrate-to-target distances.

more homogeneous thickness distribution. The rotation of the target, in our case $10 \mathrm{~Hz}$, has almost no influence in the spatial distribution, because of the large particle velocity in the $z$ direction. Only in the case of clusters and heavy species does one expect some effect.

\subsection{Droplet problem}

The normalized droplet density shows according to Fig. 6 a smooth dependence on the laser energy density. It can be seen that a threshold energy for the occurrence of droplets is found at about $0.9 \mathrm{~J} \mathrm{~cm}^{-2}$. The dependence of $\bar{N}$ on $E$ at constant spot size is not quite convincing, although, for the small spot size of $0.8 \mathrm{~mm}^{2}, \bar{N}$ is more or less proportional to $E$. The measurements in Table 3 show that $\bar{N}$ is strongly dependent on the spot size at constant laser energy. It turned out that $\bar{N}$ is roughly proportional to $1 / S$, accounting for the threshold energy of $0.9 \mathrm{~J} \mathrm{~cm}^{-2}$. At larger $S$ the behaviour of the pressure wave changes, resulting in an increase in the thickness of the deposited layer and for a smaller splashing effect.

Our particle distribution and droplet studies are performed on silicon substrates at ambient temperature. The results for in-situ grown $\mathrm{YBa}_{2} \mathrm{Cu}_{3} \mathrm{O}_{7-\jmath}$ films on single-crystal substrates show similar effects. With the process conditions for minimum droplet density it is possible to deposit standard $\mathrm{YBa}_{2} \mathrm{Cu}_{3} \mathrm{O}_{7-\delta} 100 \mathrm{~nm}$ thick layers with a number of droplets, which can be restricted to one or two on an area of $500 \mu \mathrm{m}^{2}$. Figure 7 shows a photograph of an $\mathrm{YBa}_{2} \mathrm{Cu}_{3} \mathrm{O}_{7-d}$ film of $80 \mathrm{~nm}$ on $\mathrm{SrTiO}_{3}$. No droplets can be seen.

Accurate examination of the surface quality of insitu-grown, nearly droplet-free layers by scanning electron microscopy and optical microscopy shows remarkable results. The pictures taken from the surface of the films, deposited at temperatures above $700{ }^{\circ} \mathrm{C}$, clearly show exposed "outgrowths", small areas $(0.2$ $\mu \mathrm{m})$ peaking out of the surface. The outgrowths are mainly $\mathrm{YBa}_{2} \mathrm{Cu}_{3} \mathrm{O}_{7-\delta}$ with different crystal axis orientations as found by Wu et al. [9]. In a separate paper, more attention will be paid to this subject [10].

\section{Conclusions}

It is found that the distribution of the deposited material on the substrate is influenced by the laser energy density $E$ and the spot size $S$ of the beam at the target. The maximum value of the film thickness depends linearly on $E$ and quadratically on $S$. A sharp focus of the laser beam on the target has therefore to be avoided. The lateral distribution on the substrate consists of two contributions: one is due to a sharply forward-peaked deposition and the second is the standard $\cos \theta$ behaviour of conventional thermal processes. The positioning of the substrate close to the target leads to a large inhomogeneity in the layer thickness. If the substrate is located at the outer edge of the plasma, the distribution becomes more smooth although, on the contrary, the film thickness decreases.

Also the droplet density turned out to depend on the 
TABLE 4. The maximum thicknesses of the deposited layer and the (normalized) droplet densities with constant spot size and laser energy, varying the distance between the target and substrate

\begin{tabular}{|c|c|c|c|c|c|c|}
\hline $\begin{array}{l}\text { Laser } \\
\text { energy } \\
(\mathrm{mJ})\end{array}$ & $\begin{array}{l}\text { Spot } \\
\text { size } S \\
\left(\mathrm{~mm}^{2}\right)\end{array}$ & $\begin{array}{l}\text { Energy } \\
\text { density } \\
\left(\mathrm{J} \mathrm{cm}^{-2}\right)\end{array}$ & $\begin{array}{l}\text { Maximum } \\
\text { thickness } \\
(\mathrm{nm})\end{array}$ & $\begin{array}{l}\text { Target-to- } \\
\text { substrate } \\
\text { distance } \\
(\mathrm{mm})\end{array}$ & $\begin{array}{l}\text { Number of } \\
\text { of droplets } \\
\left(100 \mu \mathrm{m}^{2}\right)\end{array}$ & $\begin{array}{l}\text { Normalized } \\
\text { number } \bar{N}\end{array}$ \\
\hline 89 & 7.15 & 1.25 & 780 & 25 & 8.0 & 10 \\
\hline 89 & 7.15 & 1.25 & 760 & 45 & 5.0 & 7 \\
\hline 89 & 7.15 & 1.25 & 570 & 55 & 1.5 & 3 \\
\hline 89 & 7.15 & 1.25 & 350 & 65 & 1.1 & 3 \\
\hline 89 & 7.15 & 1.25 & - & 75 & 0.25 & - \\
\hline
\end{tabular}
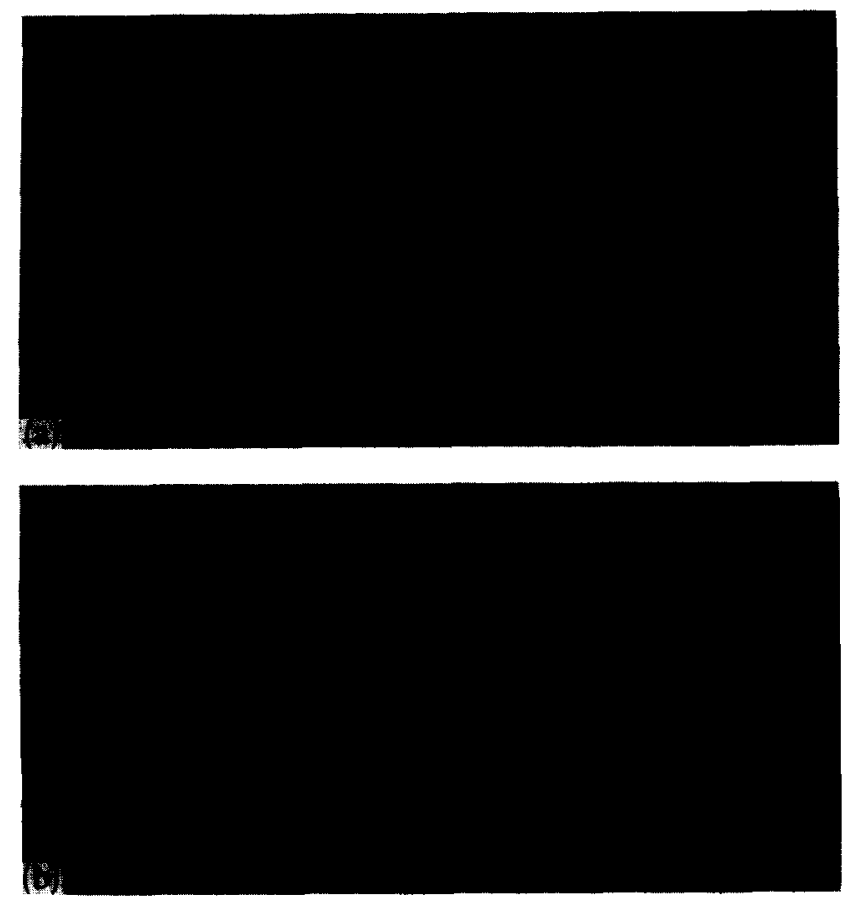

Fig. 5. Optical micrographs of layers from (a) series I and (b) series II.

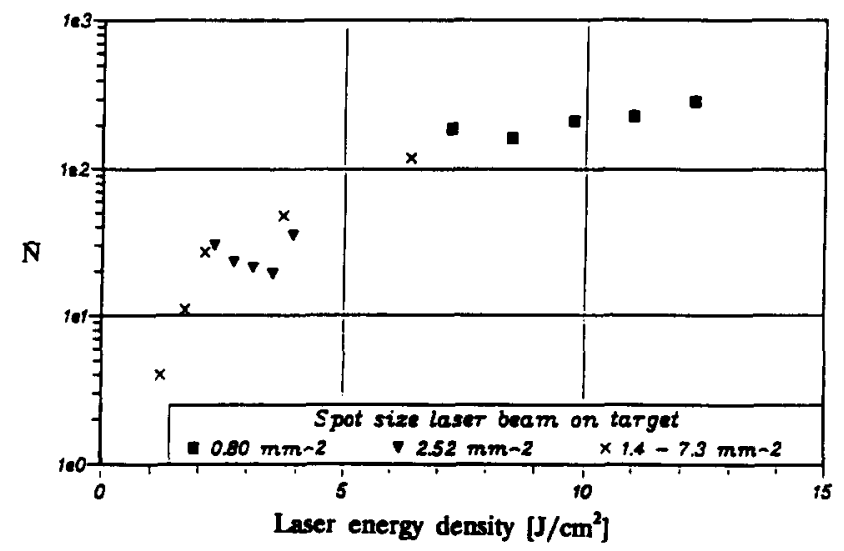

Fig. 6. The number $N$ of droplets corrected for the film thickness vs, the laser energy density.

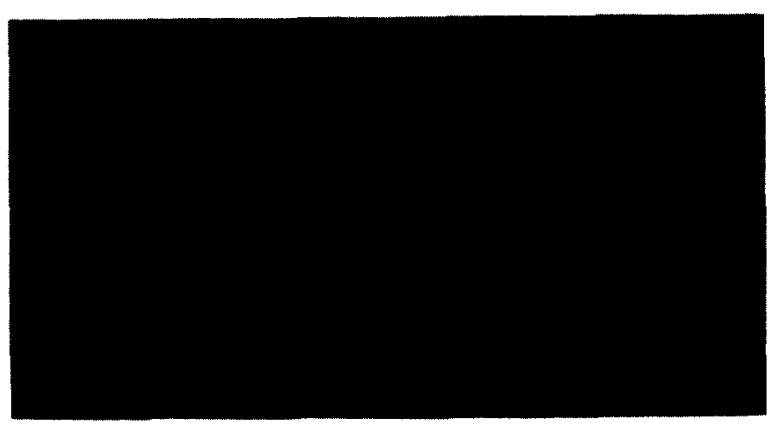

Fig. 7. Photograph of the $\mathrm{YBa}_{2} \mathrm{Cu}_{3} \mathrm{O}_{7-d}$ film deposited on $\mathrm{SrTiO}_{3}$, deposited with a laser spot size of $7.15 \mathrm{~mm}^{2}$, a laser energy of $90 \mathrm{~mJ}$ and a substrate-to-target distance of $55 \mathrm{~mm}$.

laser energy density and focus spot size. The normalized droplet density is more or less proportional to $E$ at constant $S$ and proportional to $1 / S$ at constant laser energy. A threshold energy of $0.9 \mathrm{~J} \mathrm{~cm}^{-2}$ is found for the occurrence of droplets.

Although the deposited material distribution and the droplet studies have been performed on silicon wafers at room temperature, it is found that the results are valid for the high temperature deposition of $\mathrm{YBa}_{2} \mathrm{Cu}_{3} \mathrm{O}_{7-\delta}$ layers on single-crystal substrates. However, so-called outgrowths may then occur.

\section{References}

1 G. Koren, A. Gupta, R. J. Baseman, M. I. Lutwyche and R. B. Laibowitz, Appl. Phys. Lett., 55 (1989) 2450.

2 G. Koren, R. J. Baseman, A. Gupta, M. I. Lutwyche and R. B. Laibowitz, Appl. Phys. Lett., 56 (1990) 2144.

3 J. F. Ready, Effects of High Power Laser Radiation, Academic Press, New York, 1971.

4 J. T. Cheung and H. Sankur, CRC Crit. Rev. Solid State Mater. Sci., 15 (1988) 63.

5 A. Inam, X. D. Wu, T. Venkastesan, S. B. Ogale, C. C. Chang and D. Dijkkamp Appl. Phys. Lett., 51 (1987) 1112

6 P. E. Dyer, A. Issa and P. H. Key, Appl. Phys. Lett., 57 (1990) 186. 
7 D. H. A. Blank, D. J. Adelerhof, J. Flokstra and H. Rogalla, Physica C, $167(1990) 423$.

8 D. H. A. Blank, H. Kruidhof and J. Flokstra, J. Phys. D, $2 I$ (1988) 226.

9 X. D. Wu, R. E. Muenchausen, S. Foltyn, R. C. Estler, R. C.
Dye et al., Appl. Phys. Lett., 57 (1990) 523.

10 R. P. J. IJsselsteijn, D. H. A. Blank, P. G. Out, H. J. H. Kuiper, J. Flokstra and H. Rogalla, Droplets and outgrowths on high- $T_{\mathrm{c}}$ laser ablated thin films, Proc. Eur. MRS Conf., Strasbourg, 1991. 